International Journal of Pure and Applied Mathematics

Volume 112 No. 1 2017, 57-69

ISSN: 1311-8080 (printed version); ISSN: 1314-3395 (on-line version)

url: http://www.ijpam.eu

doi: 10.12732/ijpam.v112i1.4

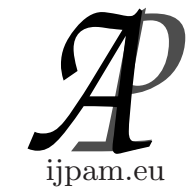

\title{
ROTATING BOUNDARY LAYER FLOW DUE TO \\ A PERMEABLE EXPONENTIALLY SHRINKING SHEET IN NANOFLUID
}

\author{
S.N.A. Salleh ${ }^{1}$, N. Bachok ${ }^{2}$, N.M. Arifin ${ }^{3}$ \\ ${ }^{1}$ Department of Mathematics and Institute for \\ Mathematical Research \\ Universiti Putra Malaysia \\ 43400 UPM Serdang, Selangor, MALAYSIA
}

\begin{abstract}
In this study, the effect of the suction on the boundary layer flow and heat transfer characteristics over an exponentially shrinking surface in a rotating nanofluid is contemplated for three types of nanoparticles namely, copper $\mathrm{Cu}$, titania $\mathrm{TiO}_{2}$ and alumina $\mathrm{Al}_{2} \mathrm{O}_{3}$. Similarity transformations have been applied to transform the partial differential equations into a system of ordinary differential equations, which are then solved numerically using a shooting method in Maple software. The effects of the rotation $\Omega$, suction $\mathbf{S}$ and nanoparticle volume fraction $\phi$ parameters on the velocity field, temperature distribution, local skin friction coefficients and local Nusselt number are taken into account. Results obtain in this study are graphically presented and further discussion have been discussed in detail. The dual solutions are found to exist for a certain values of the governing parameters. It is revealed from the study that the presence of the rotation would increase the skin friction coefficients and heat transfer rate at the surface.
\end{abstract}

AMS Subject Classification: 76D10, 76U05, 80A20

Key Words: exponentially shrinking sheet, nanofluid, rotating flow, suction

\section{Introduction}

The deliberation of the rotating flow and heat transfer in the boundary layer

Received: $\quad$ June 28, 2016

Revised: October 5, 2016

Published: January 17, 2017

$\S$ Correspondence author
(C) 2017 Academic Publications, Ltd. url: www.acadpubl.eu 
flow over a stretching sheet have earned a huge number of response by many researcher. The term of heat transfer was recognizable in industrial and engineering proposes due to the heating and cooling processes. Some common applications in real world are aerodynamic extrusion of plastic sheets, cooling of an infinite metallic plate in cooling bath, the material handling conveyors, the cooling and drying of paper and so forth. In order to get the good quality of the final product, heat transfer rate at the stretched surface is carefully observed during the manufacturing process. The fluid flow past a stretching sheet was first explored by [1], where an exact analytical solution to the Navier-Stokes equations was reported. Later, [2] extend the problem to a permeable surface subject to blowing and suction. Nowadays, the various aspects involving the boundary layer flow of a rotating fluid over a stretching surface have been considered by some authors such as [3], [4] and [5]. In summation, the problems relate to the magnetic field have been focused by [6], [7] and [8].

The above mentioned ideas, however, have not been discussed with the nanofluid yet. Therefore, [9] came out with the problem of the rotating flow in a nanofluid over a stretching surface. Nanofluid is a fluid with a suspended nanoparticles that show significant enhancement of their properties. [10] was the first who introduced the term nanofluid in the real world application in fluid dynamic. He concluded that the addition of a very small amount $(<1 \%$ volume fraction) of nanoparticles to conventional heat transfer fluid enhance the thermal conductivity of the fluid up to two times. The convectional heat transfer fluids like water, ethylene-glycol and mineral oil have low thermal conductivity which inadequate to achieve the qualification of the cooling rate. The nanoscale particles are dissolved in a base fluid, which are later known as a nanofluid. These fluid are used as an alternative way to enhance the heat transfer of such fluids. The convective heat transfer is an important appearance in industrial and engineering processes due to its applications in automotive cooling applications, heat exchangers and electronic cooling. Recent years, many works involving nanofluid have been found in the literature. [11] presented the stagnation-point flow of a nanofluid over a stretching sheet. While, [12], [13] and [14] have considered a several aspects involving the nanofluid.

However, less consideration have been given to the problems of the rotating boundary layer flow and heat transfer induced by a shrinking surface. The flow of the viscous fluid was studied by [15] due to a shrinking sheet in the presence of suction. The flow towards a shrinking sheet is found to exist, whenever an adequate suction on a boundary layer is imposed, [16] or a stagnation-point flow is considered, [17]. The study reveals that the mass suction is required to maintain the flow over a shrinking sheet. Later [18], [19] and [20] have discussed 
the effects of the MHD over a shrinking surface in a rotating fluid. Recently, [21] performed the rotating flow over an exponentially shrinking sheet with mass suction at the surface. The idea of an exponentially shrinking sheet was first considered by [22] in a viscous fluid and have been extend by [23], [24], [25], [26] and [27] in several aspects.

The desire of the present paper is to combine the idea of the rotating flow in a nanofluid by [9] over an exponentially shrinking sheet, [22] with suction effect at the surface. The governing partial differential equations are transformed into a set of ordinary differential equations using a similarity transformation in exponential form, before being solved numerically using a shooting method. The problem is fixed for Prandtl number $\operatorname{Pr}=6.2$ (water).

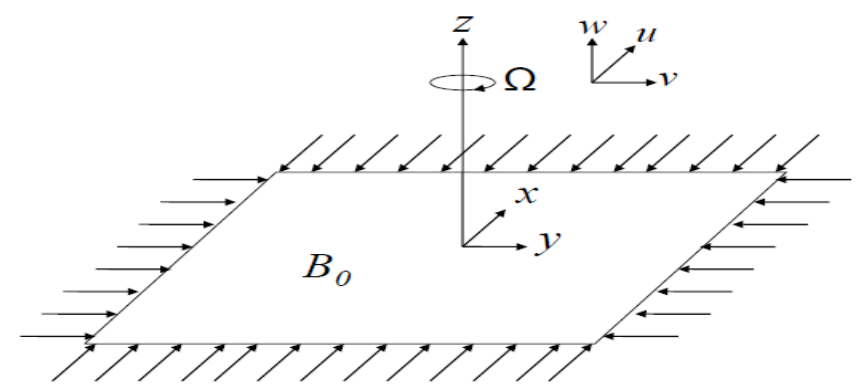

Figure 1: Physical model and coordinate system

\section{Problem Formulation}

Let us consider the steady three-dimensional rotating flow over an exponentially shrinking surface with mass suction in a water based nanofluid at $z=0$. The physical model and coordinate system of the problem is shown in Figure 1. Three different types of nanoparticles namely copper $\mathrm{Cu}$, titania $\mathrm{TiO}_{2}$ and alumina $\mathrm{Al}_{2} \mathrm{O}_{3}$ are considered. We assume $u, v$, and $w$ be the velocity components along the $x, y$, and $z$ directions, respectively. Under these assumptions, the equations represent the rotating flow and heat transfer are given by

$$
\begin{gathered}
\frac{\partial u}{\partial x}+\frac{\partial v}{\partial y}+\frac{\partial w}{\partial z}=0 \\
u \frac{\partial u}{\partial x}+v \frac{\partial u}{\partial y}+w \frac{\partial u}{\partial z}-2 \bar{\Omega} v=\frac{\mu_{n f}}{\rho_{n f}}\left(\frac{\partial^{2} u}{\partial z^{2}}\right)
\end{gathered}
$$




$$
\begin{gathered}
u \frac{\partial v}{\partial x}+v \frac{\partial v}{\partial y}+w \frac{\partial v}{\partial z}+2 \bar{\Omega} v=\frac{\mu_{n f}}{\rho_{n f}}\left(\frac{\partial^{2} v}{\partial z^{2}}\right) \\
u \frac{\partial T}{\partial x}+v \frac{\partial T}{\partial y}+w \frac{\partial T}{\partial z}=\alpha_{n f}\left(\frac{\partial^{2} T}{\partial z^{2}}\right)
\end{gathered}
$$

subject to the boundary conditions

$$
\begin{gathered}
u=-U e^{x / L}, v=0, w=-w_{o} e^{x / 2 L}, T=T_{w} \quad \text { at } z=0, \\
u \rightarrow 0, v \rightarrow 0, T \rightarrow T_{\infty} \quad \text { as } \quad z \rightarrow \infty
\end{gathered}
$$

where $w_{0}$ is the constant mass flux with $w_{0}<0$ for suction and $w_{0}>0$ for injection, the - sign represent a shrinking constant and $\bar{\Omega}=\Omega_{0} e^{x / L}$ is assumed to be the angular velocity of the rotating fluid. $T_{\infty}$ is ambient temperature, $T_{w}$ is wall temperature and $T$ is the temperature of the fluid. The dynamic viscosity, density, thermal diffusivity and thermal conductivity of the nanofluid are given by $\mu_{n f}, \rho_{n f}, \alpha_{n f}$ and $k_{n f}$, respectively and $k_{f}$ is thermal conductivity of the base fluid. All these parameters related to the nanoparticle volume fraction given as follows

$$
\begin{gathered}
\rho_{n f}=\rho_{f}\left[1-\varphi+\varphi\left(\frac{\rho_{s}}{\rho_{f}}\right)\right], \quad \mu_{n f}=\frac{\mu_{f}}{(1-\varphi)^{2.5}} \\
\alpha_{n f}=\frac{k_{n f}}{\left(\rho C_{\rho}\right)_{n f}},\left(\rho C_{\rho}\right)_{n f}=\left(\rho C_{\rho}\right)_{f}\left[1-\varphi+\varphi \frac{\left(\rho C_{\rho}\right)_{s}}{\left(\rho C_{\rho}\right)_{f}}\right] \\
\frac{k_{n f}}{k_{f}}=\frac{k_{s}+2 k_{f}-2 \varphi\left(k_{f}-k_{s}\right)}{k_{s}+2 k_{f}+\varphi\left(k_{f}-k_{s}\right)}
\end{gathered}
$$

Here, $\left(\rho C_{\rho}\right)_{s},\left(\rho C_{\rho}\right)_{f}$, and $\left(\rho C_{\rho}\right)_{n f}$ represents the volumetric heat capacities of solid nanoparticles, base fluid and nanofluid, respectively. Whereas, $\rho_{f}$ and $\mu_{f}$ are respectively, the density and dynamic viscocity of base fluid and $k_{s}$ is thermal conductivity of solid nanoparticles.

We are now introducing the following similarity transformations in exponential form:

$$
\begin{gathered}
u=U e^{\frac{x}{L}} f^{\prime}(\eta), \quad v=U e^{\frac{x}{L}} h(\eta), \quad w=-\left(\frac{U \nu_{f}}{2 L}\right)^{\frac{1}{2}} e^{\frac{x}{2 L}}\left[f(\eta)+\eta f^{\prime}(\eta)\right], \\
\eta=\left(\frac{U}{2 \nu_{f} L}\right)^{\frac{1}{2}} e^{\frac{x}{2 L}} z, \quad \theta(\eta)=\frac{T-T_{\infty}}{T_{w}-T_{\infty}}
\end{gathered}
$$

where primes refer as the differentiation with respect to $\eta$. 
Using the above transformations, Eq. (1) is satisfied and Eqs. become the following ordinary differential equations as shown below

$$
\begin{gathered}
\frac{1}{(1-\varphi)^{2.5}\left[1-\varphi+\varphi\left(\rho_{s} / \rho_{f}\right)\right]} f^{\prime \prime \prime}+f f^{\prime \prime}-2 f^{\prime 2}+4 \Omega h=0 \\
\frac{1}{(1-\varphi)^{2.5}\left[1-\varphi+\varphi\left(\rho_{s} / \rho_{f}\right)\right]} h^{\prime \prime}+f h^{\prime}-2 f^{\prime} h-4 \Omega f^{\prime}=0 \\
\frac{1}{\operatorname{Pr}} \frac{k_{n f} / k_{f}}{\left[1-\varphi+\varphi\left(\rho C_{\rho}\right)_{s} /\left(\rho C_{\rho}\right)_{f}\right]} \theta^{\prime \prime}+f \theta^{\prime}=0
\end{gathered}
$$

subjected to the boundary conditions (5) which become

$$
\begin{gathered}
f(0)=s, \quad f^{\prime}(0)=-1, \quad h(0)=0, \theta(0)=1 \\
f^{\prime}(\eta) \rightarrow 0, \quad h(\eta) \rightarrow 0, \quad \theta(\eta) \rightarrow 0 \quad \text { as } \eta \rightarrow \infty
\end{gathered}
$$

$\operatorname{Pr}=\nu / \alpha$ is the Prandtl number, $\Omega=\Omega_{0} L / U$ is a nondimensional rotation parameter and $s$ is the constant mass flux parameter with $s>0$ for suction and $s<0$ for injection.

The local skin friction coefficients in the $x$ and $y$ directions and the local Nusselt number can be expressed as

$$
C f_{x}=\frac{\tau_{x z}}{\rho_{f}\left(U e^{\frac{x}{L}}\right)^{2}}, \quad C f_{y}=\frac{\tau_{y z}}{\rho_{f}\left(U e^{\frac{x}{L}}\right)^{2}}, \quad N u_{x}=\frac{L q_{w}}{k_{f}\left(T_{w}-T_{\infty}\right)},
$$

where the shear stress of $x$ and $y$ component $\tau_{x z}, \tau_{y z}$ and heat flux $q_{w}$ are given by

$$
\tau_{x z}=\mu_{n f}\left(\frac{\partial u}{\partial z}\right)_{z=0}, \quad \tau_{y z}=\mu_{n f}\left(\frac{\partial v}{\partial z}\right)_{z=0}, \quad q_{w}=-k_{n f}\left(\frac{\partial T}{\partial z}\right)_{z=0}
$$

Using Eq. (6) - (7) and Eq. (13), Eq. (12) becomes

$$
\begin{gathered}
\left(2 R e_{x}\right)^{1 / 2} C f_{x}=\frac{1}{(1-\varphi)^{2.5}} f^{\prime \prime}(0), \quad\left(2 R e_{x}\right)^{1 / 2} C f_{y}=\frac{1}{(1-\varphi)^{2.5}} h^{\prime}(0), \\
\left(\sqrt{2} R e_{x}^{-1 / 2}\right) N u_{x}=\frac{-k_{n f}}{k_{f}} \theta^{\prime}(0)
\end{gathered}
$$

where $R e_{x}=U L e^{x / L} / \nu_{f}$ is refer as the local Reynolds number. 
Table 1: Thermophysical properties of the base fluid and nanoparticles

\begin{tabular}{ccccc}
\hline Physical properties & Fluid phase & $\mathrm{Cu}$ & $\mathrm{Al}_{2} \mathrm{O}_{3}$ & $\mathrm{TiO}_{2}$ \\
\hline$C_{\rho}(\mathrm{J} / \mathrm{kg} \mathrm{K})$ & 4179 & 385 & 765 & 686.2 \\
$\rho\left(\mathrm{kg} / \mathrm{m}^{3}\right)$ & 997.1 & 8933 & 3970 & 4250 \\
$k(\mathrm{~W} / \mathrm{mk})$ & 0.613 & 400 & 40 & 8.9538 \\
\hline
\end{tabular}

\section{Result and Discussion}

Equations (8) - (10) associated with the conditions (11) were solved numerically via a shooting method in Maple software.The unknown values of $f^{\prime \prime}(0), h^{\prime}(0)$ and $-\theta^{\prime}(0)$ are set as an initial guesses in which all the profiles must satisfy the conditions (11) asymptotically with the different shapes. The physical parameters involved in this study are rotation parameter $\Omega$, suction parameter $s$ and nanoparticle volume fraction parameter $\varphi$. We take the Prandtl number as $\operatorname{Pr}=6.2$ (water) and nanoparticle volume fraction is considered from 0 to 0.2 $(0 \leq \varphi \leq 0.2)$ according to [28] in which $\varphi=0$ is refer as a regular fluid. Table 1 presents the thermophysical properties of the base fluid and nanoparticles used in the present study.

Figures $2-4$ show the variations of the reduced skin friction of $x$ and $y$ component $f^{\prime \prime}(0), h^{\prime}(0)$ and local heat flux $-\theta^{\prime}(0)$ with suction $s$ for several values of rotation $\Omega$ for $\mathrm{Cu}$-water when $\varphi=0.1$. The values of $f^{\prime \prime}(0), h^{\prime}(0)$ and $-\theta^{\prime}(0)$ are seem to increase as the $\Omega$ increases. The side effect of increasing the rotation in the fluid flow will reduce the momentum boundary layer thickness which leads to increase both the shear stress of $x$ components, $f^{\prime \prime}(0)$ and $y$ components, $h^{\prime}(0)$ on the surface, respectively. When the values of $\Omega$ are small enough $(\Omega=0.015)$, the dual solutions are found to exist for $s \geq 2.2640$ and beyond this interval no solutions appear. $s_{c}$ represents the critical values of $s$ for which Eqs. (8) - (10) has no solutions.

Figures 5 - 7 displays the influence of the nanoparticle volume fraction on the variations of $f^{\prime \prime}(0), h^{\prime}(0)$ and $-\theta^{\prime}(0)$ with $s$ for $\mathrm{Cu}$-water when $\Omega=0.015$. Figures 5 - 6 indicate that as the values of $\varphi$ increase, the variations of $f^{\prime \prime}(0)$ and $h^{\prime}(0)$ increase significantly. While in Fig. 7, the reverse effect occurs for the $-\theta^{\prime}(0)$. The values of $s_{c}$ for different values of $\varphi$ are shown in Table 2 . When the values of $\varphi$ increase, the values of $s_{c}$ are found to decrease. However, increase the values of $s$ will increase the values of $s_{c}$. This is due to the fact that, suction widens the range for which the solutions exist.

Figures 8 - 10 show the variations of $\left(2 R e_{x}\right)^{1 / 2} C f_{x},\left(2 R e_{x}\right)^{1 / 2} C f_{y}$ and 


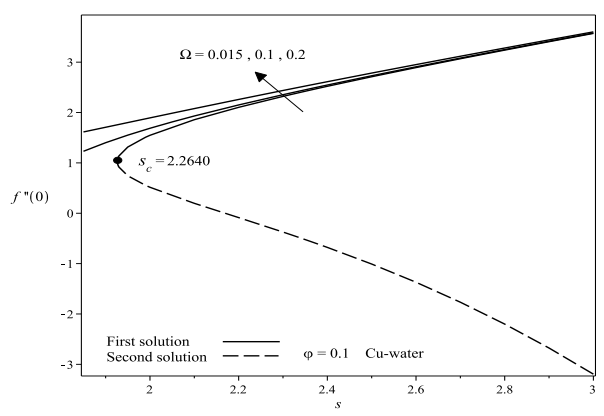

Figure 2: Variation of $f^{\prime \prime}(0)$ with $s$ for different $\Omega$ for $\mathrm{Cu}$-water when $\varphi=0.1$.

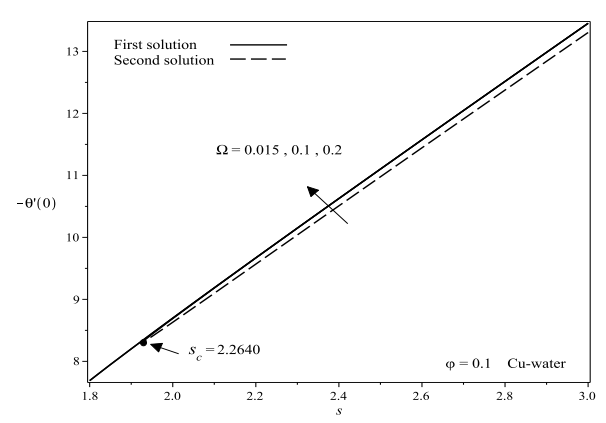

Figure 4: Variation of $-\theta^{\prime}(0)$ with $s$ for different $\Omega$ for $\mathrm{Cu}$-water when $\varphi=0.1$.

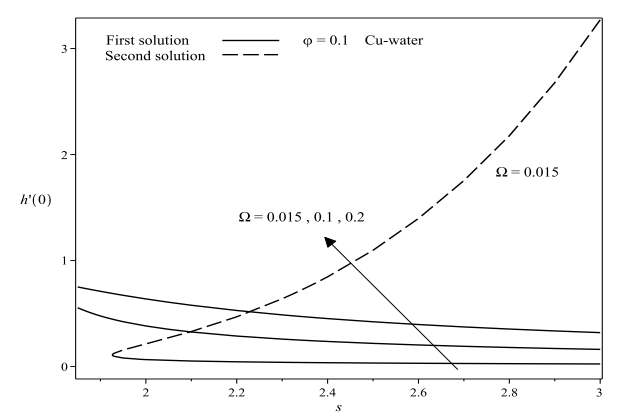

Figure 3: Variation of $h^{\prime}(0)$ with $s$ for different $\Omega$ for $\mathrm{Cu}$-water when $\varphi=0.1$.

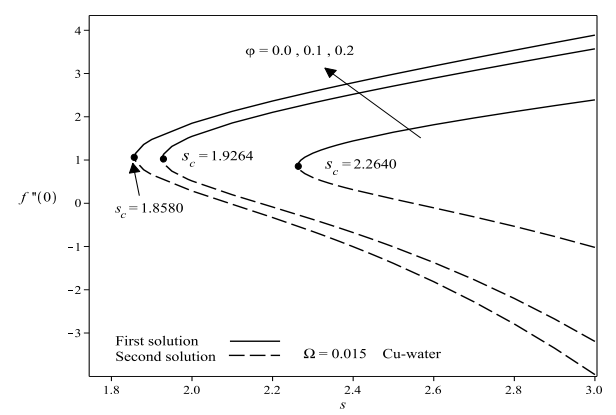

Figure 5: Variation of $f^{\prime \prime}(0)$ with $s$ for different $\varphi$ for $\mathrm{Cu}$-water when $\Omega=0.015$.

Table 2: Variations of $s_{c}$ for different values of nanoparticle volume fraction $\varphi$ for $\mathrm{Cu}$-water when $\Omega=0.015$

\begin{tabular}{cc}
\hline$\varphi$ & Values of $s_{c}$ \\
\hline 0.0 & 2.2640 \\
0.1 & 1.9264 \\
0.2 & 1.8580 \\
\hline
\end{tabular}

$\left(\sqrt{2} R e_{x}^{-1 / 2}\right) N u_{x}$ with $\varphi$ for different nanoparticles and for various values of $\Omega$ when $s=2.5$. As the values of $\Omega$ and $\varphi$ increase, the skin friction coefficients for both $x$ and $y$ component increases. The presence of the rotation in 
the fluid flow will accelerate the fluid motion and causes the reduction of the momentum boundary layer thickness. This is due to the collision between the base fluid particles and nanoparticles. These kind of behaviors will increase the shear stress at the wall thus leads to increase the skin friction coefficient. However in Fig. 10, as the $\varphi$ increase the local Nusselt number are found to decrease, while the opposite effect can be observed as the $\Omega$ increase. It is found from Fig. 10 that the lowest heat transfer rate is obtained for $\mathrm{TiO}_{2}$ due to domination of conduction mode of heat transfer. This follow the fact that $\mathrm{TiO}_{2}$ has the lowest value of thermal conductivity compared with $\mathrm{Al}_{2} \mathrm{O}_{3}$ and $\mathrm{Cu}$. However, the thermal conductivity of $\mathrm{Al}_{2} \mathrm{O}_{3}$ is approximately one tenth of $\mathrm{Cu}$. The comparison values of the thermal conductivity of nanoparticles are tabulated in Table 1.

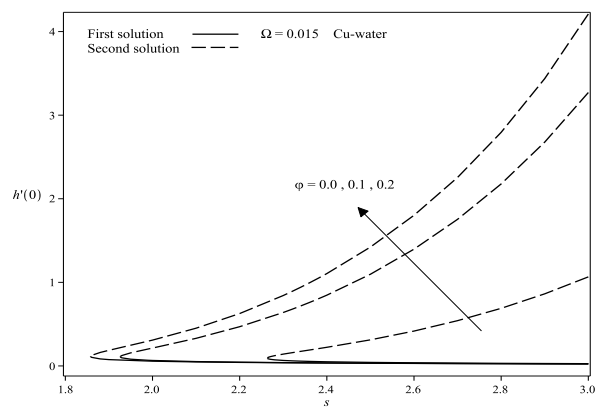

Figure 6: Variation of $h^{\prime}(0)$ with $s$ for different $\varphi$ for $\mathrm{Cu}$-water when $\Omega=0.015$.

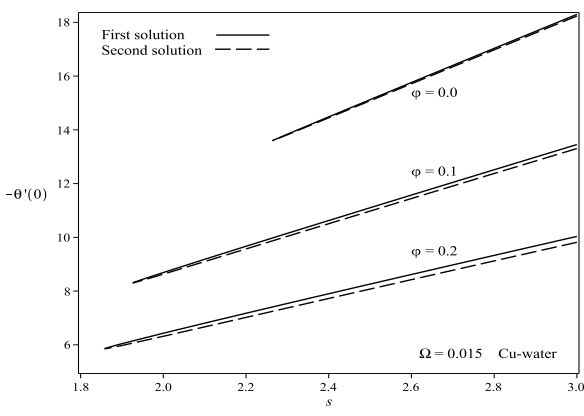

Figure 7: Variation of $-\theta^{\prime}(0)$ with $s$ for different $\varphi$ for $\mathrm{Cu}$-water when $\Omega=0.015$.

The sample of the profiles are shown in Figs. $11-16$ for different values of $\Omega$ and $s$. From Figs. $11-12$, it is noticed that the values of $f^{\prime}(\eta)$ and $h(\eta)$ increases as the $\Omega$ increase, while in Fig. 13 the opposite trend is observed for $\theta(\eta)$. In summation, Fig. 14 indicate that increase the values of $s$ results in an increase in the values of $f^{\prime}(\eta)$ for the first solution and decrease for the second solution. Whereas the effect of the $h(\eta)$ are opposite and it is shown in Fig. 15. Fig. 16 show that the values of $\theta(\eta)$ decreases as the values of $s$ increase and these will make the thermal boundary layer thickness reduced. Figures 11 - 16 show that all the profiles have satisfied the conditions (11) asymptotically and these behaviors will support the accuracy of the numerical results obtained in this study. 


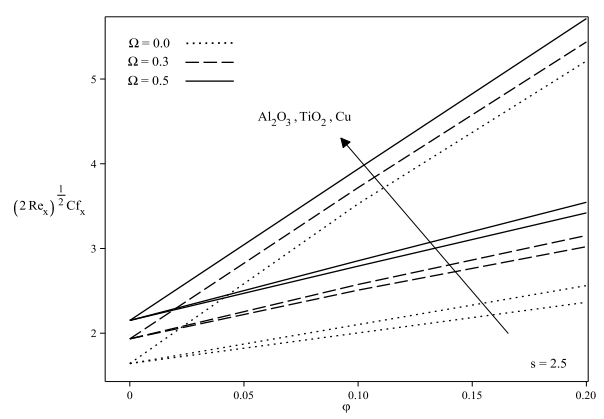

Figure 8: Variation of the skin friction coefficient of $x$-component with $\varphi$ for different nanoparticles and $\Omega$ when $s=2.5$.

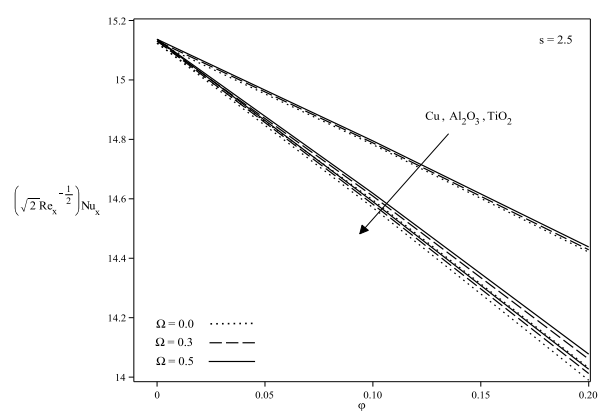

Figure 10: Variation of the local Nusselt number with $\varphi$ for different nanoparticles and $\Omega$ when $s=2.5$.



Figure 9: Variation of the skin friction coefficient of $y$-component with $\varphi$ for different nanoparticles and $\Omega$ when $s=2.5$.

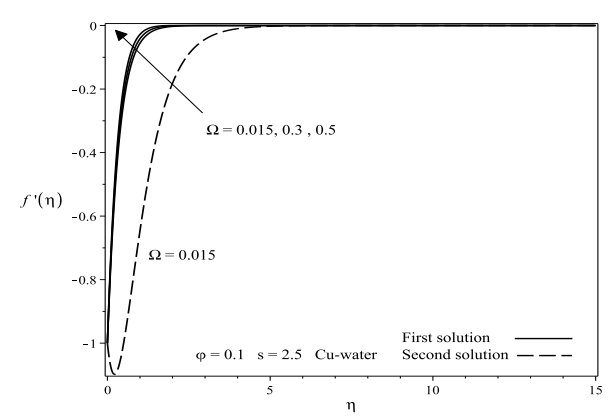

Figure 11: Velocity profiles $f^{\prime}(\eta)$ for different $\Omega$ for $\mathrm{Cu}$-water when $\varphi=$ 0.1 and $s=2.5$.

\section{Conclusion}

The problem involving the rotating flow over an exponentially shrinking sheet immersed in nanofluid with suction has been considered in this study. The set of ordinary differential equations have been transformed using the similarity transformation, before being solved numerically using a shooting method in Maple software. The results obtain in this study can be summarized as follow:

- increase the rotation parameter would increase the skin friction coefficients in both $x$ and $y$ component as well as local Nusselt number. 


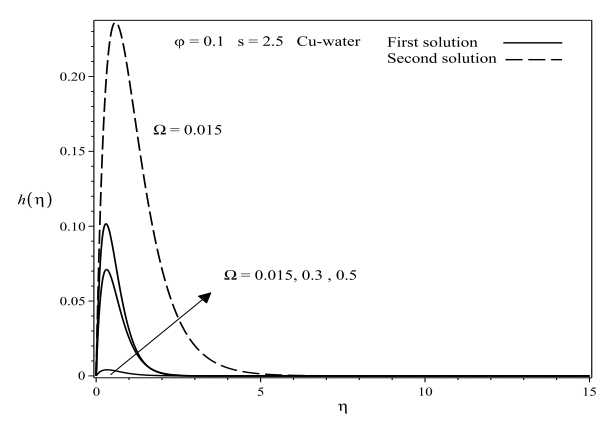

Figure 12: Velocity profiles $h(\eta)$ for different $\Omega$ for $\mathrm{Cu}$-water when $\varphi=$ 0.1 and $s=2.5$.

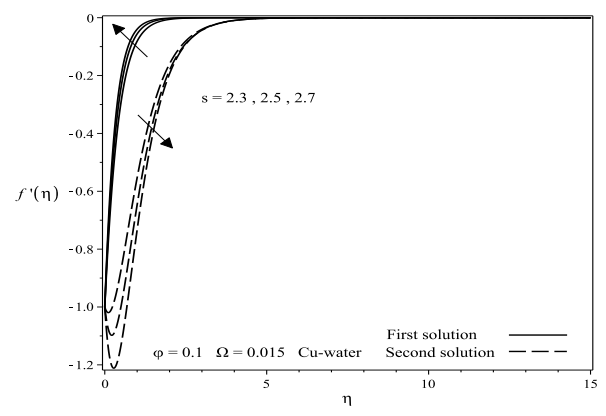

Figure 14: Velocity profiles $f^{\prime}(\eta)$ for different $s$ for $\mathrm{Cu}$-water when $\varphi=$ 0.1 and $\Omega=0.015$.

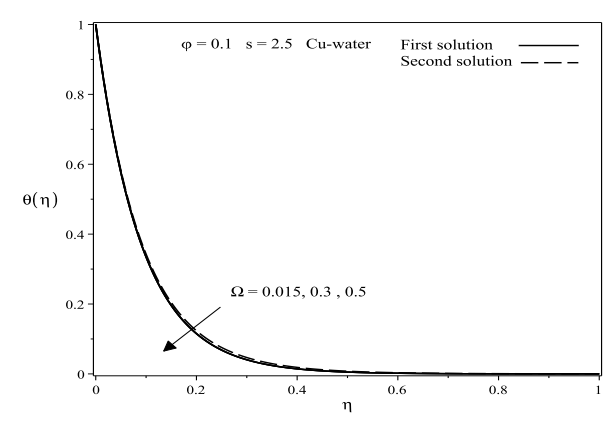

Figure 13: Temperature profiles $\theta(\eta)$ for different $\Omega$ for $\mathrm{Cu}$-water when $\varphi=0.1$ and $s=2.5$.

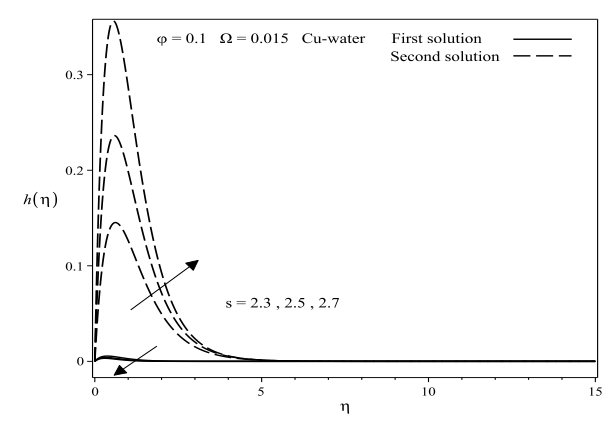

Figure 15: Velocity profiles $h(\eta)$ for different $s$ for $\mathrm{Cu}$-water when $\varphi=$ 0.1 and $\Omega=0.015$.

- increase the nanoparticle volume fraction results in an increase the skin friction coefficients in both $x$ and $y$ component, while the opposite trend is observed for the local Nusselt number.

- if the mass suction exceeds a certain value, i.e. $s \geq s_{c}$, the steady rotating flow due to an exponentially shrinking surface is possible and dual solution for velocity fields and temperature distribution were found. Besides, velocity increases with $s$ for the first solution and decreases for second solution of $x$ components. However, reverse effects occur for $y$ components. The temperature distribution are seem to be decreased for both solutions with an increment of suction. 


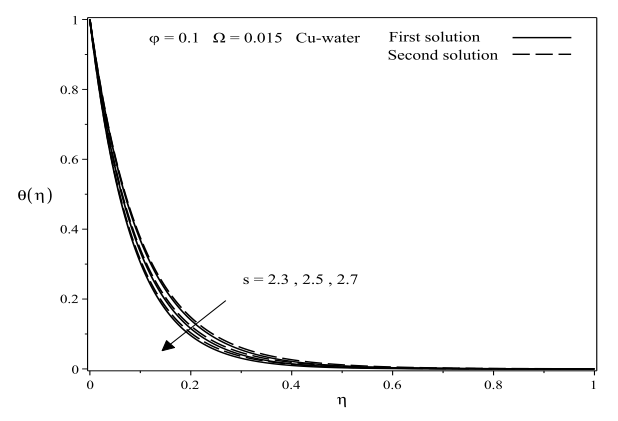

Figure 16: Velocity profiles $h(\eta)$ for different $s$ for $\mathrm{Cu}$-water when $\varphi=$ 0.1 and $\Omega=0.015$.

\section{References}

[1] L.J. Crane, Flow past a stretching plate, Z Angew Math. Phys., 21, (1970), 645-647, doi: 10.1007/BF01587695.

[2] P. Gupta, A. Gupta, Heat and mass transfer on a stretching sheet with suction and blowing, The Can. J. of Chem. Eng., 55, No. 6 (1977), 744-746, doi: 10.1002/cjce.5450550619.

[3] C.Y. Wang, Stretching a surface in a rotating fluid, J. App. Maths. and Phys., 39, (1988), 177-185, doi: 10.1007/BF00945764.

[4] V. Rajeswari, G. Nath, Unsteady flow over a stretching surface in a rotating fluid, Int. J. of Eng. Sci., 30, No. 6 (1992), 747-756, doi: 10.1016/0020-7225(92)90104-O.

[5] R. Nazar, N. Amin, I. Pop, Unsteady boundary layer flow due to a sretching surface in a rotating fluid, Mechanics Research Communications, 31, (2004), 121-128, doi: 10.1016/j.mechrescom.2003.09.004.

[6] H. Takhar, A. Chamkha, G. Nath, Flow and heat transfer on a stretching surface in a rotating fluid with a magnetic field, Int. J. of Thermal Sciences, 42, (2003), 23-31, doi: 10.1016/S1290-0729(02)00004-2.

[7] Z. Abbas, T. Javed, N. Ali, Unsteady MHD flow and heat transfer on a stretching sheet in a rotating fluid, J. of the Taiwan Inst. of Chem. Eng., 41, (2010), 644-650, doi: 10.1016/j.jtice.2010.02.002.

[8] T. Mahmood, S. Ali, M. Khan, Magnetohydrodynamic flow due to a stretching surface in rotating fluid, Journal of Mathematics, 46, No. 1 (2014), 39-50.

[9] S. Nadeem, A. Rehman, R. Mehmood, Boundary layer flow of rotating two phase nanofluid over a stretching surface, Heat Transfer Asian Research, 45, (2016), 285-298, doi: $10.1002 / \mathrm{htj} .21167$.

[10] S.U.S Choi, Enhancing thermal conductivity of fluids with nanoparticles, ASME Publication, 66, (1995), 99-101.

[11] M. Mustafa, T. Hayat, I. Pop, S. Asghar, S. Obaidat, Stagnation-point flow of a nanofluid towards a stretching sheet, Int. J. of Heat and Mass Transfer, 54, (2011), 5588-5594, doi: 10.1016/j.ijheatmasstransfer.2011.07.021. 
[12] O.D. Makinde, W.A. Khan, Z.H. Khan, Buoyancy effects on MHD stagnationpoint flow and heat transfer of a nanofluid past a convectively heated stretching/shrinking sheet, Int. J. of Heat and Mass Transfer, 62, (2013), 526-533, doi: 10.1016/j.ijheatmasstransfer.2013.03.049.

[13] N. Bachok, A. Ishak, R. Nazar, N. Senu, Stagnation-point flow over a permeable stretching/shrinking sheet in a copper-water nanofluid, Boundary Value Problems, 39, (2013), doi: 10.1186/1687-2770-2013-39.

[14] S.V. Subhashini, R. Sumathi, Dual solutions of a mixed convection flow of nanofluids over a moving vertical plate, Int. J. of Heat and Mass Transfer, 71, (2014), 117-124, doi: 10.1016/j.ijheatmasstransfer.2013.12.034.

[15] F. Ali, R. Nazar, N.M. Arifin, I. Pop, Unsteady shrinking sheet with mass transfer in a rotating fluid, Int. J. 7 for Numerical Methods in Fluids, 66, (2011), 1465-1474, doi: 10.1002/fld.2325.

[16] M. Miklavcic, C.Y. Wang, Viscous flow due to a shrinking sheet, Quarterly of Applied Mathematics, 64, No. 2 (2006), 283-290.

[17] C.Y. Wang, Stagnation flow towards a shrinking sheet, Int. J. of Non-Lin. Mech., 43, (2008), 377-382, doi: 10.1016/j.ijnonlinmec.2007.12.021.

[18] M. Sajid, T. Javed, T. Hayat, Mhd rotating flow of a viscous fluid over a shrinking surface, Nonlinear Dynamics, 51, (2008), 259-265, doi: 10.1007/s11071-007-9208-3.

[19] T. Hayat, T. Javed, M. Sajid, Analytic solution for MHD rotating flow of a second grade fluid over a shrinking surface, Physics Letters A, 372, (2008), 3264-3273, doi: 10.1016/j.physleta.2008.01.069.

[20] N. Faraz, Y. Khan, Analytical solution of electrically conducted rotating flow of a second grade fluid over a shrinking surface, Ain Shams Engineering Journal, 2, (2011), 221-226, doi: 10.1016/j.asej.2011.10.001.

[21] H. Rosali, A. Ishak, R. Nazar, I. Pop, Rotating flow over an exponentially shrinking sheet with suction, Journal of Molecular Liquids, 211, (2015), 965-969, doi: 10.1016/j.molliq.2015.08.026.

[22] K. Bhattacharyya, Boundary layer flow and heat transfer over an exponentially shrinking sheet, Chin. Phys. Letter, 28, No. 7 (2011), 74701-4, doi: 10.1088/0256307X/28/7/074701.

[23] K. Bhattacharyya, I. Pop, Mhd boundary layer flow due to an exponentially shrinking sheet, Magnetohydrodynamics, 47, No. 4 (2011), 337-344.

[24] N. Bachok, A. Ishak, I. Pop, Boundary layers stagnation-point flow and heat transfer over an exponentially stretching/shrinking sheet in a nanofluid, Int. J. of Heat and Mass Transfer, 55, (2012), 8122-8128, doi: 10.1016/j.ijheatmasstransfer.2012.08.051.

[25] K. Bhattacharyya, K. Vajravelu, Stagnation-point flow and heat transfer over an exponentially shrinking sheet, Commun Nonlinear Sci Numer Simulation, 17, (2012), 27282734, doi: 10.1016/j.cnsns.2011.11.011.

[26] A.M. Rohni, S. Ahmad, A.I. Ismail, I. Pop, Boundary layer flow and heat transfer over an exponentially shrinking vertical sheet with suction, Int. J. of Thermal Sciences, 64, (2013), 264-272, doi: 10.1016/j.ijthermalsci.2012.08.016. 
[27] M.M. Rahman, A.V. Rosca, I. Pop, Boundary layer flow of a nanofluid past a permeable exponentially shrinking/stretching surface with second order slip using buongiornos model, Int. J. of Heat and Mass Transfer, 77, (2014), 1133-1143, doi: 10.1016/j.ijheatmasstransfer.2014.06.013.

[28] H.F. Oztop, E. Abu-Nada, Numerical study of natural convection in partially heated rectangular enclosures filled with nanofluids, Int. J. Heat Fluid Flow, 29, (2008), 13261336, doi: 10.1016/j.ijheatfluidflow.2008.04.009. 
